\title{
Two-Year Follow-Up Study of the Effect of Acid Fog on Adult Asthma Patients
}

\author{
Hiroshi Tanaka, Shin-ichi Honma, Motoi Nishi*, \\ Tomofumi IGARASHi**, Fumihiko NiSHIO*** and Shosaku ABE
}

\begin{abstract}
Acid fog is a complex mixture of atomospheric pollutants containing multiple stimuli that may be capable of inducing bronchoconstriction. To investigate the effect of ambient acid fog on bronchoconstriction, we examined the relation between the hospital visit for asthma symptoms of 102 patients and various meteorological conditions for over the two-year period from January 1992 to December 1993. Dense fog occurs frequently every summer in Kushiro, a city located in Hokkaido, northernmost island in Japan. The acidity of the fog ranged from pH 3.32 to 6.91 (mean $\mathrm{pH}=5.05)$ during this period. A significant increase $(\mathbf{p}<0.05)$ of hospital visits on a foggy day was found in 9 cases, and a tendency $(p<0.10)$ was found in 10 cases. The odds ratio for a hospital visit on a high water vapor pressure day $(>12 \mathrm{hPa})$ was significantly high $(\mathrm{p}<0.01)$ in 5 cases among the above 19 cases. To exclude the effect of high water vapor pressure, the data was restricted to the condition of a foggy day with low water vapor pressure $(<12 \mathrm{hPa}) ; 9$ patients had a significant increase $(p<0.05)$ in hospital visits on such a day. These results indicated that hospital visits for asthma symptoms was increased on acid fog days in $8.8 \%$ of adult asthma patients. Inhalation of naturally occurring acid fog may have adverse effects on the respiratory tract of the asthmatic patient.
\end{abstract}

(Internal Medicine 35: 100-104, 1996)

Key words: acid aerosol, air pollutant, bronchial asthma, weather factor

\section{Introduction}

Weather-related factors alone may induce a response in asthmatics. The response may be due to the changing the concentration of airborne pollutants. Naturally occurring fog has recently been shown to be quite acidic, with $\mathrm{pH}$ values as low as under 2.0 (1). The major ions present in acid fog are hydrogen, sulfate, nitrate, ammonium and chloride $(1,2)$, suggesting that the low $\mathrm{pH}$ is in large part due to the presence of sulfuric $\left(\mathrm{H}_{2} \mathrm{SO}_{4}\right)$ and nitric $\left(\mathrm{HNO}_{3}\right)$ acid. However, the potential adverse health effects of breathing acid fog have not been adequately examined $(3,4)$.

Exposure to acidic aerosols and sulfates has been associated with increased respiratory mortality, morbidity and symptoms in a variety of settings $(3,5-8)$. Chamber exposure studies suggest that asthma patients are more sensitive to the acidic sulfates than normal volunteers (9-11). On the other hand, some reports $(12,13)$ revealed that healthy adults and asthmatic subjects have shown little or no bronchoconstriction in methacholine reactivity after acute exposure to $\mathrm{H}_{2} \mathrm{SO}_{4}$ fog. Overall, the results of chamber exposure studies suggested that asthmatics might be an appropriate "sensitive population" to airborne acid aerosol $(3,8)$.

Kushiro is a city of 200,000 residents located on the Pacific coast in the northeastern Japan. It has little industry. Dense fog frequently occurs there every summer. Daily fog acidity in the Kushiro urban area was measured in 1992 by the group of Nishio, one of the author of this paper. The fog acidity is quite acidic there; the annual average fog $\mathrm{pH}$ was 4.94 and the minimum was 3.32 in 1992.

To investigate the effects of acid fog on adult asthmatics, we conducted a retrospective study of the correlation between the hospital visits for asthma symptoms and various meteorological conditions.

\footnotetext{
From the Third Department of Internal Medicine, *the Department of Public Health, Sapporo Medical University School of Medicine, Sapporo, **the Division of Respiratory Medicine, Kushiro City General Hospital, Kushiro and ***Hokkaido University of Education, Kushiro

Received for publication June 28, 1995; Accepted for publication October 27, 1995

Reprint requests should be addressed to Dr. Hiroshi Tanaka, the Third Department of Internal Medicine, Sapporo Medical University School of Medicine, South-1, West-16, Chuo-ku, Sapporo 060
} 


\section{Materials and Methods}

A total of 102 physician diagnosed asthmatics (15-79 yearold, 45 males and 57 females) were eligible to participate in this study. All patients were Kushiro residents and were followed at Kushiro City General Hospital for two years from January 1992 to December 1993. The asthma severity (14) of the 102 patients was as follows; 9 severe, 53 moderate and 40 mild subjects. Forty patients were treated with theophylline and inhaled salbutamol, 62 patients received inhaled beclomethasone dipropionate $(300-1,200 \mu \mathrm{g} /$ day $)$ and 8 cases were administered oral prednisolone. When the patient had at least one of the following criteria they were defined as atopic; 1 ) one or more positive skin prick tests, 2) a total serum IgE level of more than $500 \mathrm{U} / \mathrm{ml}, 3$ ) one or more positive specific serum IgE tested by the commercial kit (MAST systems, Hitachi Kasei, Tokyo, Japan). In the light of this criteria, 58 patients were considered as atopic and 44 patients were non-atopic.

Individual extra hospital visits for asthma symptoms including emergency room visits at night were picked up retrospectively from the patient's medical record. Asthma symptoms were wheezing, shortness of breath, chest tightness or cough.

The following daily meteorological data were obtained from the Kushiro Meteorological Observatories; fog occurrence, barometric pressure, temperature, water vapor pressure, relative humidity, wind velocity, wind direction and precipitation. Fog was gathered with a large screen collector and the acidity of the fog water was measured with a $\mathrm{pH}$ meter. The levels of daily air pollutants in this area, for example suspended particulate matter of less than $10 \mu \mathrm{m}, \mathrm{SO}_{2}, \mathrm{NO}, \mathrm{NO}_{2}$, ozone, were all within the Ambient Air Quality Standards of the Environment Agency of Japan (15).

\section{Statistical analysis}

Each meteorological variable was divided into two categories (Table 1). Observed and expected individual hospital visits related to the above various meteorological factors for category " 1 " in Table 1 was using chi-square test. Odds ratio for each meteorological variable to category " 1 " in Table 1 was also calculated in each patient using the method of Mantel and Haenzel (16).

\section{Results}

Fog occurred 380 days during the study period from January 1992 to December 1993. The fog acidity could be measured 51 days; it ranged from $\mathrm{pH} 3.32$ to 6.91 . The mean $\mathrm{pH}$ was 5.05 and SD was 0.69 .

Percent increase of hospital visit as related to each meteorological condition is shown in Table 2 . The rate was the highest $(9 / 102)$ on foggy days, the second rate $(7 / 102)$ was observed on high vapor pressure $(\geqq 12 \mathrm{hPa})$ days and the third value $(6 / 102)$ was observed on low barometric pressure $(<1,000 \mathrm{hPa})$ days. Nine patients ( 2 severe, 5 moderate and 2 mild) visited the hospital in significant correlation $(\mathrm{p}<0.05)$ with fog and 10 patients ( 3 severe, 2 moderate and 5 mild) had a tendency
Table 1. Categorization of Meteorological Parameters

\begin{tabular}{lcc}
\hline Meteorological parameter & 1 & 0 \\
\hline Fog & Yes & No \\
Barometric pressure & $\geqq 1,000 \mathrm{hPa}$ & $<1,000 \mathrm{hPa}$ \\
$\begin{array}{l}\text { Daily temperature difference } \\
\quad \text { (max minus min) }\end{array}$ & $\geqq 10^{\circ} \mathrm{C}$ & $<10^{\circ} \mathrm{C}$ \\
$\begin{array}{l}\text { Day-to-day temperature difference } \\
\quad \text { (max of previous day minus min) }\end{array}$ & $\geqq 10^{\circ} \mathrm{C}$ & $<10^{\circ} \mathrm{C}$ \\
Water vapor pressure & $\geqq 12 \mathrm{hPa}$ & $<12 \mathrm{hPa}$ \\
Relative humidity (mean) & $\geqq 90 \%$ & $<90 \%$ \\
Relative humidity (minimum) & $>75 \%$ & $<75 \%$ \\
Wind velocity (mean) & $\geqq 4 \mathrm{~m}$ & $<4 \mathrm{~m}$ \\
Wind velocity (maximum) & $\geqq 9 \mathrm{~m}$ & $<9 \mathrm{~m}$ \\
Wind direction at maximal velocity & South & North, East, West \\
Precipitation & $\geqq 1 \mathrm{~mm}$ & $<1 \mathrm{~mm}$ \\
\hline
\end{tabular}

Table 2. Percent Increase of Hospital Visits in Various Meteorological Conditions

Meteorological parameter

\begin{tabular}{lcc} 
Meteorological parameter & $\begin{array}{c}\text { Percent increase of hospital visit } \\
\text { (mo }\end{array}$ & $0^{*}$ \\
\hline Fog & 8.8 & 3.9 \\
Barometric pressure & 0 & 5.9 \\
Daily temperature difference & 2.0 & 1.0 \\
$\quad$ (max minus min) & 0 & 3.9 \\
Day-to-day temperature difference & & \\
$\quad$ (max of previous day minus min) & 6.9 & 3.9 \\
Water vapor pressure & 2.0 & 1.0 \\
Relative humidity (mean) & 4.9 & 1.0 \\
Relative humidity (minimum) & 1.0 & 2.0 \\
Wind velocity (mean) & 1.0 & 2.0 \\
Wind velocity (maximum) & 2.9 & 1.0 \\
Wind direction at maximal velocity & 0 & 1.0 \\
Precipitation & & \\
\hline
\end{tabular}

*Each category was shown in Table 1.

$(\mathrm{p}<0.10)$ to visit the hospital on a foggy day. The characteristics of these patients are shown in Table 3.

The odds ratios to various meteorological conditions in the above 19 patients are shown in Tables 4 and 5 . Odds ratio to high vapor pressure equal to and higher than $12 \mathrm{hPa}$ was significantly high $(\mathrm{p}<0.01)$ in 5 cases in 19 cases respectively. The odds ratio of high mean relative humidity ( $\geqq 90 \%$ ) was significantly high $(\mathrm{p}<0.01)$ in 3 cases and that of high minimum relative humidity $(\geqq 75 \%)$ was also significantly high $(\mathrm{p}<0.01)$ in 5 cases. For the other meteorological conditions, three had significantly $(\mathrm{p}<0.01)$ increased hospital visits on south wind days and another patient had significantly $(\mathrm{p}<0.01)$ increased visits on high mean wind velocity $(\geqq 4 m)$ days.

To exclude the effect of high vapor pressure, the data was restricted to conditions of vapor pressure under $12 \mathrm{hPa}$ and 
TANAKA et al

Table 3. Characteristics of Asthmatics with Fog-related Symptoms and the Results of Chi-square Test

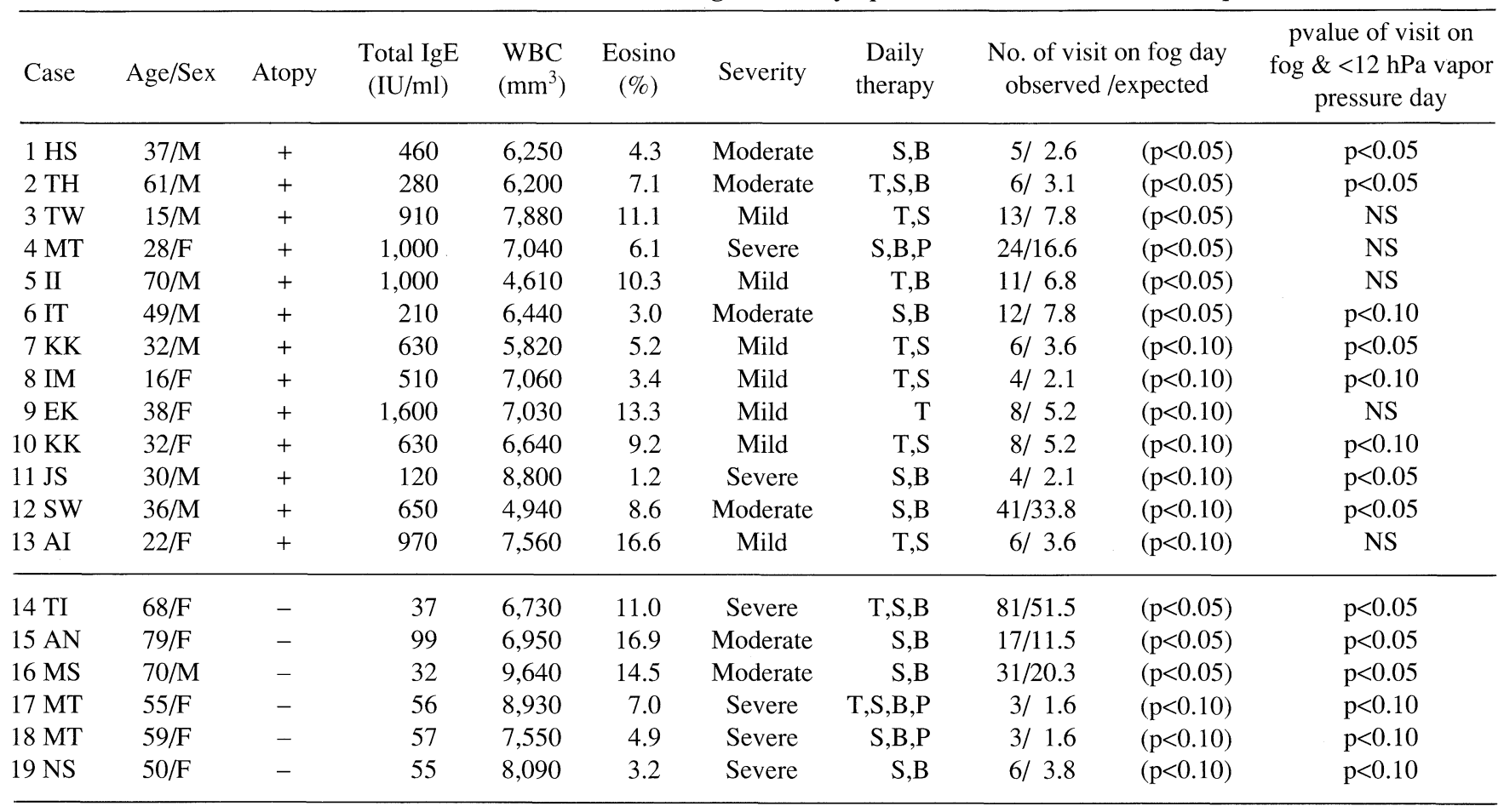

T: theophylline, $\mathrm{S}$ : inhaled salbutamol as required, B: inhaled beclomethasone dipropionate, $\mathrm{P}$ : oral prednisolone, NS: $\mathrm{p}>0.10$.

foggy days; 9 cases (30-79 year-old, 2 severe, 6 moderate and 1 mild) showed significantly increased $(\mathrm{p}<0.05)$ visits and 5 cases ( 2 severe, 1 moderate and 2 mild) had a tendency of increased $(\mathrm{p}<0.10)$ visits (Table 3$)$. Overall, 19 out of 102 patients $(18.6 \%)$ had a tendency toward increased hospital visits. When the data was restricted to the day of fog occurrence and low water vapor pressure, the hospital visits were significantly $(\mathrm{p}<0.05)$ increased in nine patients $(8.8 \%)$ in this study population.

\section{Discussion}

The present results suggest that inhalation of acid fog might increase asthma symptoms; $8.8 \%$ of adult asthma patients had an increase of hospital visits for asthma symptoms in our study population. And the percent increase of hospital visits on a foggy day was the highest among other meteorological parameters. There have been no studies on the prevalence of the effect of naturally occurring acid fog in asthmatics or residents. In this study, all of the participants were carrying out typical daily life and thus some patients may not have been outdoors and they did not inhale acid fog equally. If all the patients had inhaled an equal amount of fog, the number might have been increased. Hospital visits based on the asthma symptoms, as a parameter of the fog effect is a relatively crude measure of the actual response to the fog and may reflect events only in minor subjects. If we calculate the number of symptoms from the patient's diary or daily peak expiratory flow rate (17), the percentage of the effect of acid fog might also increase.
In our study, the hospital visits on a foggy day with low water vapor pressure was significantly increased $(\mathrm{p}<0.05)$ in 9 cases. There was no significant difference in age, treatment or disease severity between these 9 patients and the other 93 patients. We hypothesized that the number of hospital visit in non-atopic patients might be more increased than that of atopic patients, because atopic patients exacerbate by inhalation of causative antigen, the trend of the effect of acid fog is more clearly apparent in non-atopic subjects than in atopic subjects. However, there was no difference between these two types.

We could not analyze all types of fog; diffuse or short-lived fogs did not provide enough condensate to examine $\mathrm{pH}$ and ions. In a few samples we measured the anions of the fog; for example the condensate on September 3, 1992 contained 30 ppm of $\mathrm{SO}_{4}{ }^{2-}, 15 \mathrm{ppm}$ of $\mathrm{NO}_{3}{ }^{-}$and $10 \mathrm{ppm}$ of $\mathrm{NO}_{2}{ }^{-}$. The proportion of these anions showed daily variation but the trend of the content of these ions did not change in several types of fog water. The major ions reported to be present in acid fog are hydrogen, sulfate, nitrate, ammonium and chloride $(1,2)$ and the low $\mathrm{pH}$ is due to the presence of sulfuric and nitric acid. Glotfelty et al (18) reported a variety of pesticides and their toxic alteration products in fog. Hydroxymethanesulfonic acid, the bisulfite $\left(\mathrm{HSO}_{3}{ }^{-}\right)$adduct of formaldehyde $\left(\mathrm{CH}_{2} \mathrm{O}\right)$ was a common constitutent of California acid fogs (19). No tests were conducted specifically for pesticides or their products in Kushiro. Since not only ions but also other acidic materials that have an adverse effect, it is of interest to elucidate the unknown materials that lower fog $\mathrm{pH}$.

The odds ratio to variable meteorological factors revealed 
Effect of Acid Fog on Asthmatics

Table 4. Odds Ratio of Hospital Visits for Meteorological Variables on Atopic Asthmatics

\begin{tabular}{|c|c|c|c|c|c|c|c|}
\hline \multicolumn{2}{|c|}{ Meteorological parameter } & 1. HS & 2. $\mathrm{TH}$ & $\begin{array}{l}\text { Patient } \\
\text { 3. TW }\end{array}$ & 4. MT & 5. II & 6. IT \\
\hline \multicolumn{2}{|l|}{ 1. Fog } & $>50(\mathrm{p}<0.05)$ & $>50(\mathrm{p}<0.01)$ & $6.18(\mathrm{p}<0.01)$ & $2.89(\mathrm{p}<0.01)$ & $5.20(\mathrm{p}<0.01)$ & $3.78(\mathrm{p}<0.05)$ \\
\hline \multicolumn{2}{|c|}{ 2. Barometric pressure } & (NS) & (NS) & (NS) & (NS) & (NS) & (NS) \\
\hline \multicolumn{2}{|c|}{$\begin{array}{l}\text { 3. Daily temperature difference } \\
\text { (max minus min) }\end{array}$} & (NS) & (NS) & (NS) & (NS) & (NS) & (NS) \\
\hline \multicolumn{2}{|c|}{$\begin{array}{l}\text { 4. Day-to-day temperature difference } \\
\text { (max of previous day minus min) }\end{array}$} & (NS) & (NS) & (NS) & (NS) & (NS) & (NS) \\
\hline \multicolumn{2}{|c|}{ 5. Water vapor pressure } & (NS) & (NS) & $11.3(\mathrm{p}<0.01)$ & $2.84(\mathrm{p}<0.01)$ & $38.3(\mathrm{p}<0.01)$ & $5.61(\mathrm{p}<0.01)$ \\
\hline \multicolumn{2}{|c|}{ 6. Relative humidity (mean) } & (NS) & $6.68(\mathrm{p}<0.01)$ & (NS) & (NS) & (NS) & $3.87(\mathrm{p}<0.01)$ \\
\hline \multicolumn{2}{|c|}{ 7. Relative humidity (minimum) } & (NS) & $5.79(\mathrm{p}<0.01)$ & (NS) & (NS) & (NS) & (NS) \\
\hline \multicolumn{2}{|c|}{ 8. Wind velocity (mean) } & (NS) & (NS) & (NS) & (NS) & $6.67(\mathrm{p}<0.01)$ & (NS) \\
\hline \multicolumn{2}{|c|}{ 9. Wind velocity (maximum) } & (NS) & (NS) & (NS) & (NS) & (NS) & (NS) \\
\hline \multicolumn{2}{|c|}{ 10. Wind direction at max velocity } & (NS) & (NS) & (NS) & (NS) & (NS) & $4.70(\mathrm{p}<0.01)$ \\
\hline \multicolumn{2}{|c|}{ 11. Precipitation } & (NS) & (NS) & (NS) & (NS) & (NS) & (NS) \\
\hline $\begin{array}{l}\text { Meteorological } \\
\text { parameter }\end{array}$ & 7. KK & 8. IM & 9. EK & $\begin{array}{l}\text { Patient } \\
\text { 10. KK }\end{array}$ & 11. JS & 12. SW & 13. AI \\
\hline 1. & $5.61(\mathrm{p}<0.10)$ & $>50(\mathrm{p}<0.10)$ & $3.75(\mathrm{p}<0.10)$ & $>50(\mathrm{p}<0.10)$ & $>50(\mathrm{p}<0.10)$ & $1.64(\mathrm{p}<0.10)$ & $5.61(\mathrm{p}<0.10)$ \\
\hline 2. & (NS) & (NS) & (NS) & (NS) & (NS) & (NS) & (NS) \\
\hline 3. & (NS) & (NS) & (NS) & (NS) & (NS) & (NS) & (NS) \\
\hline 4. & (NS) & (NS) & (NS) & (NS) & (NS) & $(\mathrm{NS})$ & (NS) \\
\hline 5. & (NS) & (NS) & (NS) & (NS) & (NS) & (NS) & (NS) \\
\hline 6. & (NS) & (NS) & (NS) & $>50(\mathrm{p}<0.10)$ & (NS) & (NS) & (NS) \\
\hline 7. & (NS) & (NS) & (NS) & (NS) & (NS) & (NS) & (NS) \\
\hline 8. & (NS) & (NS) & (NS) & (NS) & (NS) & (NS) & (NS) \\
\hline 9. & (NS) & (NS) & (NS) & (NS) & (NS) & (NS) & (NS) \\
\hline 10. & (NS) & (NS) & (NS) & (NS) & (NS) & (NS) & (NS) \\
\hline 11. & (NS) & (NS) & (NS) & (NS) & (NS) & (NS) & (NS) \\
\hline
\end{tabular}

Odds ratio for " 1 " of each category in Table 1.

NS: $p \geqq 0.10$

Table 5. Odds Ratio of Hospital Visits for Meteorological Variables in Non-atopic Asthmatics

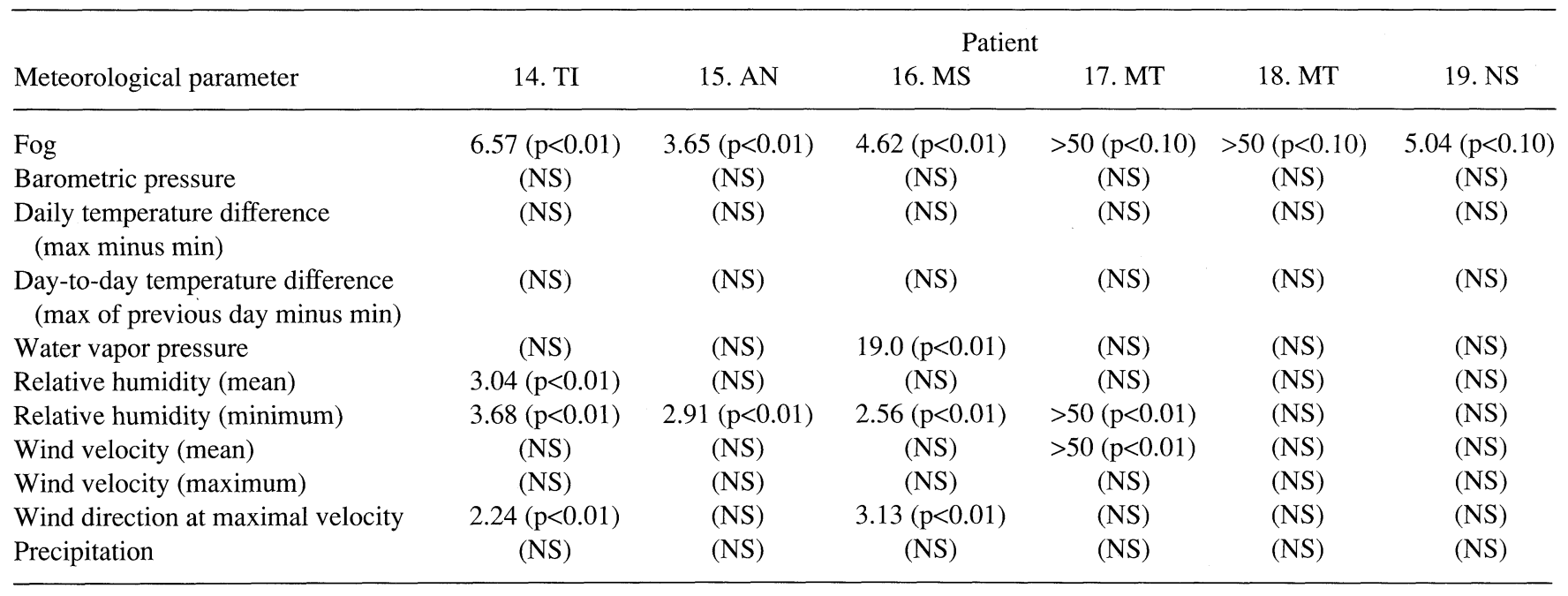

Odds ratio to " 1 " of each category in Table 1.

NS: $p \geqq 0.10$ 
individual variations as shown in Tables 4 and 5. Weather factors may induce a direct physiological response or a psychologically mediated response. Cold, damp, or windy/dusty weather conditions are often thought to exacerbate asthma, but epidemiologic evidence relating asthma attacks to short-time weather changes is equivocal (20). Temperature and relative humidity are the weather factors most easily isolated and studied in the laboratory. The short-term effects of relative humidity have been elucidated in studies of exercise-induced bronchoconstriction (21). Among the 19 patients with an increase of hospital visits on foggy days, no cases had a high odds ratio for the change of temperature, and 6 patients had a significantly high $(\mathrm{p}<0.01)$ odds ratio for high relative humidity. Not all patients with fog-related symptoms grew more serious on a high relative humidity day. These findings suggested that inhalation of naturally occurring fog itself might be an adverse factor exacerbating asthma symptoms.

\section{References}

1) Jacob DJ, Waldman JW, Munger JW, Hoffman MR. Chemical composition of fog water collected along the California coast. Environ Sci Technol 18: 827, 1985.

2) Waldman JM, Munger JW, Jacob DJ, Flagan RC, Morgan JJ, Hoffman MR. Chemical composition of acid fog. Science 218: 677, 1982.

3) Balmes JR, Fine JM, Gordon T, Sheppard D. Potential bronchoconstrictor stimuli in acid fog. Environ Health Perspect 79: 163, 1989.

4) Ostro BD, Lipset MJ, Wiener MB, Selner JC. Asthmatic response to airborne acid aerosols. Am J Public Health 81: 694, 1991.

5) Thurston GD, Ito K, Lippmann M, Hayes C. Reexamination of London, England, mortality in relation to exposure to acidic aerosols during 19631971 winters. Environ Health Perspect 79: 73, 1988.

6) Ware JH, Ferris BG, Dockery DW, Spengler JD, Stram DO, Speizer FE. Effects of ambient sulfur oxides and suspended particles on respiratory health of preadolescent children. Am Rev Respir Dis 133: 834, 1986.
7) Bates DV, Sizto R. The ontario air pollution study: Identification of the causative agent. Environ Health Perspect 79: 69, 1989.

8) Fine JM, Gordon T, Sheppard D. The role of titrate acidity in acid aerosolinduced bronchoconstriction. Am Rev Respir Dis 135: 826, 1987.

9) Koeening JQ, Pierson WE, Horike M. The effect of inhaled sulfuric acid on pulmonary function in adolescent asthmatics. Am Rev Respir Dis 128: 221, 1983.

10) Utell MJ. Effect of inhaled acid aerosols on lung mechanics: Analysis of human exposure studies. Environ Health Perspect 63: 39, 1985.

11) Avol EL, Linn WS, Wightman LH, Whynot JD, Anderson KR, Hackney JD. Short term respiratory effects of sulfuric acid in fog: a laboratory study of healthy and asthmatic volunteers. J Air Pollut Control Assoc 38: 258, 1988.

12) Linn WS, Avol EL, Anderson KR, Shamoo DA, Peng RC, Hackney JD. Effect of droplet size on respiratory responses to inhaled sulfuric acid in normal and asthmatic volunteers. Am Rev Respir Dis 140: 161, 1989.

13) Aris R, Christian D, Sheppard D, Balmes JR. Lack of bronchoconstrictor response to sulfuric acid aerosols and fogs. Am Rev Respir Dis 143: 744, 1991.

14) Lenfant C. Global Initiative for Asthma. in: Global Strategy for Asthma Management and Prevention NHLBI/WHO Workshop Report. NIH Publication, 1995, p.59.

15) Ambient Air Quality Standards. in: Quality of the Environment in Japan 1990. Environment Agency, Government of Japan, Tokyo, 1990, p.480.

16) Mantel N, Haenzel W. Statistical aspects of the analysis of data from retrospective studies of disease. J Natl Cancer Inst 22: 719, 1959.

17) Higgins BG, Francis HC, Yates CJ, Warburton CJ, Fletcher AM. Effects of air pollution on symptoms and peak expiratory flow measurements in subjects with obstructive airways disease. Thorax 50: 149, 1995.

18) Glotfelty DE, Seiber JN, Liljedahl LA. Pesticides in fog. Nature 325: 602, 1987.

19) Aris R, Christian D, Sheppard D, Balmes JR. Acid fog-induced bronchoconstriction. The role of hydroxymethanesulfonic acid. Am Rev Respir Dis 141: 546, 1990.

20) Barbee RA. The epidemiology of asthma. Monogr Allergy 21: 21, 1987.

21) Freed AN, Omori C, Hubbard WC, Adkinson NF Jr. Dry air- and hypertonic aerosol-induced bronchoconstriction and cellular responses in the canine lung periphery. Eur Respir J 7: 1308, 1994. 